\title{
How to provide tailored career coaching for medical students
}

\author{
Yera Hur', A Ra $\mathrm{Cho}^{2}$ and Sun $\mathrm{Kim}^{2}$ \\ ${ }^{1}$ Department of Medical Education, Konyang University College of Medicine, Daejeon, and ${ }^{2}$ Department of Medical \\ Education, The Catholic University College of Medicine, Seoul, Korea
}

Purpose: This study was performed to develop a counseling strategy, based on the profiles of medical students' Strong Interest Inventory (STRONG) and Myer-Briggs Type Indicator (MBTI) results, focusing on the three following questions: Into what distinct levels are students categorized by STRONG and MBTI? and What is the dispersion of the integrated profiles?

Methods: Freshmen students from Konyang University College of Medicine who matriculated between March 2011 and 2013 were administered the MBTI personality type test and the STRONG interest inventory assessment. The integrated profiles were categorized per Kim et al. (2006), and frequency analysis was performed with the collected data, using SPSS version 21.0.

Results: Regarding MBTI types, $16.9 \%$ of students were categorized as ESTJ, and $12.9 \%$ was ISTJ. Further, $62.4 \%$ of students were Investigative (I) according to STRONG. The integrated profiles were divided into four types, according to their unclear/clear preference in the STRONG and MBTI results. Most students had 'clear preference and clear interest' $(n=144,80.9 \%)$, six students (3.4\%) had 'clear interest but unclear preference,' and 28 students (15.7\%) showed 'unclear interest but clear preference.'

Conclusion: Using the combined results of the STRONG interest inventory assessment and MBTI tools, we can purvey more tailored information to students.

Key Words: Personality inventory, STRONG, Medical students, Counseling, Career coaching

\section{INTRODUCTION}

Medical students who enter medical school have decided on a path that is related to medicine. But after 4 to 6 years of medical education and on entering residency, they face another phase of making decisions with regard to their career. During this process, various factors influence these decisions the main factors of which include interest personality, aptitude, and interest. One study reported that satisfaction rate and overall well-being were important factors in deciding on a specialty in medicine [1]. Students must seriously consider their personal interests and aptitude. Thus, we need to provide students with opportunities to determine their interests, aptitudes, and personality during their medical education, which will give them sufficient time to explore their majors of interest a very important task in medical education.

According to recent studies, Sastre et al. [2] demonstrated that a systematic advisory program was more effective than one-on-one advising. Macaulay et al. [3]
Received: November 3, 2014 • Revised: Janurary 20, 2015 • Accepted: Janurary 22, 2015 Corresponding Author: Sun Kim (http://orcid.org/0000-0002-5152-9153)

Department of Medical Education, The Catholic University of Korea College of Medicine, 222 Banpo-daero, Seocho-gu, Seoul 137-701, Korea

Tel: +82.2.2258.7200 email: skim@catholic.ac.kr
Korean J Med Educ 2015 Mar; 27(1): 45-50. http://dx.doi.org/10.3946/kjme.2015.27.1.45 eISSN: 2005-7288

(C) The Korean Society of Medical Education. All rights reserved. This is an open-access article distributed under the terms of the Creative Commons Attribution Non-Commercial License (http:// creativecommons.org/licenses/by-nc/3.0/), which permits unrestricted non-commercial use, distribution, and reproduction in any medium, provided the original work is properly cited. 
reported that a personalized advisory dean program was better than a previous academic and career advisory program, wherein over $89 \%$ of students were satisfied with the new program. Thus, career coaching program has a significant role in medical education. Also, many studies have shown the positive effects of student coaching programs on the selection of specific majors and career choices $[4,5,6,7]$. Further, the effects and inclusion of the students' career path are dependent on the composition of the program. Thus, a lack of preparation with regard to career planning might place medical students into dilemmas or miserable situations. As a result, we need systematic, long-term career guidance, such as a tailored career coaching program, that takes recent trends, gender differences, personality differences, and other important factors into account $[8,9,10,11]$.

Traditionally, Myer-Briggs Type Indicator (MBTI) personality types and Strong Interest Inventory (STRONG) occupation interest types are frequently used for psychological inspections in career coaching. These indicators can help determine one's appropriate career and plan strategies for career coaching by creating an integrated profile. In this study, we discussed more tailored career coaching methods for medical students using the integrated profile results of the MBTI personality type test and STRONG occupation interest types, addressing several specific research questions: (1) What is the distribution of medical students' MBTI types and STRONG occupation interest types? (2) What is the distribution of the integrated profiles according to the clearness of medical student MBTI types and STRONG occupation interest types?

\section{SUBJECTS AND METHODS}

We administered the MBTI personality type test and
STRONG interest inventory assessment, targeting 180 Konyang University College of Medicine freshmen who matriculated between March 2011 and 2013. MBTI personality type was categorized as an unclear preference for scores lower than 9 points for more than 3 of 4 preference indices [12]. STRONG occupation interest type categorizes clearance using the Like Percentage (LP) and Dislike Percentage (DP) factors. The LP factor is the percentage of the numbers that are answered "like" or "right" to the total number of questions. For those with LP values of more than 53\%, the pattern is called an "elevated profile." In contrast, the DP factor is the percentage of the numbers that are answered "dislike" or "wrong" to the total number of questions. For those with DP values over 54\%, the pattern is called a "depressed profile." Persons with an "elevated profile" or a "depressed profile" are considered to have unclear STRONG occupation interest types [12]. The reliability scores of the STRONG interest inventory assessment were $0.85-0.92$ in general occupational themes, $0.75-0.93$ in basic interest scales (except for agriculture and sales scale) [13]. We categorized these profiles into four integrated strategies-Searching, Action, Counseling, and Support-using SPSS version 21.0 (IBM Corp., Armonk, USA) and performed frequency analysis with the collected data.

\section{RESULTS}

\section{Distribution of medical students' MBTI per- sonality types and STRONG occupation interest types}

In the distribution of medical students' MBTI personality types and STRONG occupation interest types, ESTJ was the most common MBTI type with 30 (16.9\%), 
followed by ISTJ (12.9\%) and ESFJ (9.6\%). Most were

Realistic (R) with 22 (12.4\%) (Table 1).

Investigative (I) STRONG type (111, 62.4\%), followed by

Table 1. Distribution of Medical Students' MBTI Personality Types and STRONG Occupation

\begin{tabular}{lccccccc}
\hline \multirow{2}{*}{ MBTI } & $\mathrm{R}$ & $\mathrm{I}$ & $\mathrm{A}$ & $\mathrm{S}$ & $\mathrm{E}$ & $\mathrm{C}$ & Total \\
\cline { 2 - 8 } ESTJ & $2(6.7)$ & $22(73.3)$ & $4(13.3)$ & $1(3.3)$ & - & $1(3.3)$ & 30 \\
ISTJ & $3(13.0)$ & $15(65.2)$ & $3(13.0)$ & - & - & $2(8.7)$ & 23 \\
ESFJ & $3(17.6)$ & $11(64.7)$ & - & $2(11.8)$ & - & $1(5.9)$ & 17 \\
ESTP & $2(13.3)$ & $11(73.3)$ & - & - & $1(6.7)$ & $1(6.7)$ & 15 \\
ENFP & $2(15.4)$ & $2(15.4)$ & $2(15.4)$ & $1(7.7)$ & $3(23.1)$ & $3(23.1)$ & 13 \\
ENTP & $2(15.4)$ & $6(46.2)$ & $2(15.4)$ & $1(7.7)$ & - & $2(15.4)$ & 13 \\
INTP & - & $9(81.8)$ & - & - & $1(9.1)$ & $1(9.1)$ & 11 \\
INTJ & $2(22.2)$ & $4(44.4)$ & $1(11.1)$ & $1(11.1)$ & - & $1(11.1)$ & 9 \\
ISFP & $1(12.5)$ & $5(62.5)$ & $1(12.5)$ & - & $1(12.5)$ & - & 8 \\
ISTP & $2(25.0)$ & $4(50.0)$ & $1(12.5)$ & $1(12.5)$ & - & - & 8 \\
INFP & - & $4(57.1)$ & $1(14.3)$ & - & $1(14.3)$ & $1(14.3)$ & 7 \\
ENTJ & - & $4(66.7)$ & - & $1(16.7)$ & - & $1(16.7)$ & 6 \\
ENFJ & $2(40.0)$ & $3(60.0)$ & - & - & - & - & 5 \\
ISFJ & - & $4(80.0)$ & - & $1(20.0)$ & - & - & 5 \\
ESFP & - & $4(100.0)$ & - & - & - & - & 4 \\
INFJ & $1(25.0)$ & $3(75.0)$ & - & - & - & - & 4 \\
Total & $22(12.4)$ & $111(62.4)$ & $15(8.4)$ & $9(5.1)$ & $7(3.9)$ & $14(7.9)$ & 178 \\
\hline
\end{tabular}

Data are presented as number $(\%)$.

MBTI: Myer-Briggs Type Indicator, STRONG: Strong Interest Inventory, R: Realistic, I: Investigative, A: Artistic, S: Social, E: Enterprising, C: Conventional.

Fig. 1. Issues and Counseling Strategies by Type of Integrated MBTI Personality and STRONG Occupation Interest Profile

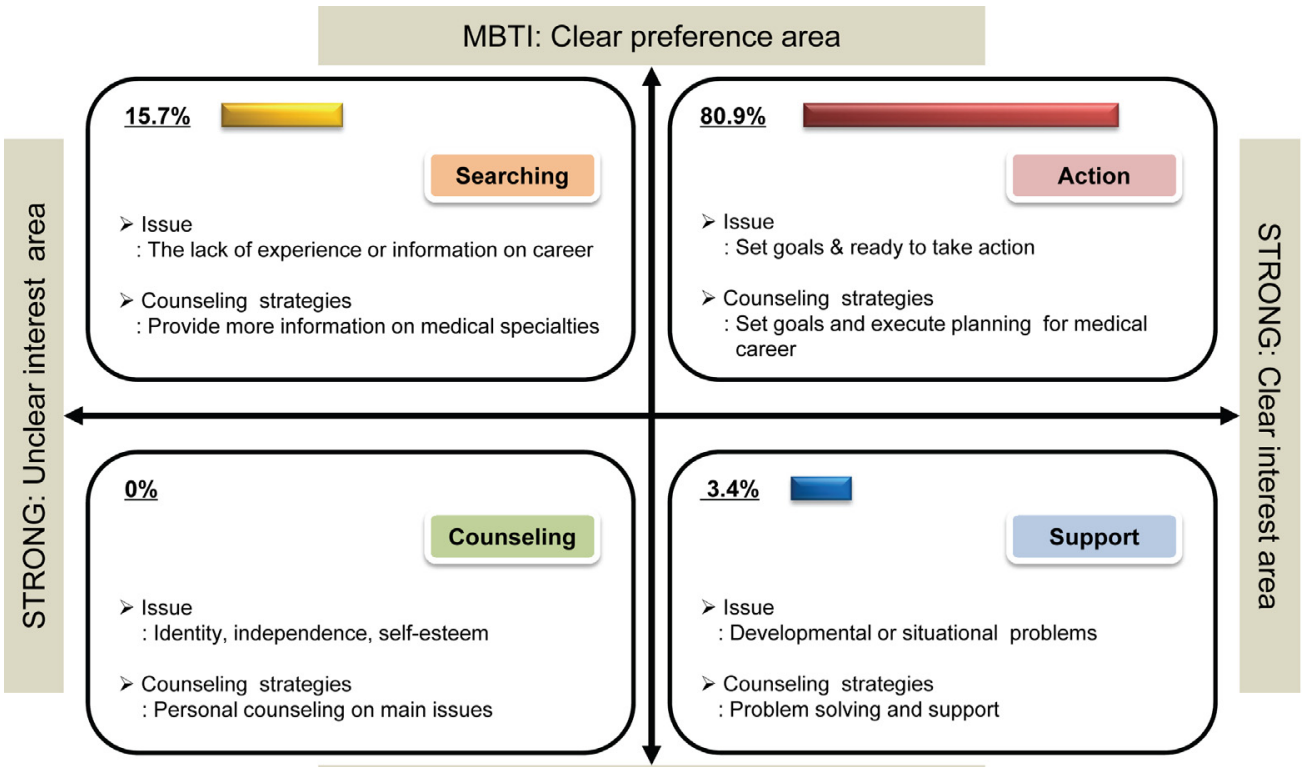

MBTI: Unclear preference area

Content partly adopted from Kim MJ, et al. User's guide STRONG \& MBTI. 2nd ed. Seoul, Korea: ASSESTA; 2006 [12]. MBTI: Myer-Briggs Type Indicator. 


\section{Distribution of integrated profiles}

In the analysis of the data from 178 responses, according to the clearness standards of MBTI personality types, we confirmed that six students (3.3\%) had an unclear preference. With STRONG occupation interest types, $29(16.1 \%)$ had an unclear occupation interest type: 11 with a "depressed profile," reflecting a high DP factor, and 18 with an "elevated profile," indicating a high LP factor.

The integrated profile of MBTI personality types and STRONG occupation interest types was a $2 \times 2$ model, with four types (Searching, Action, Counseling, and Support). With regard to medical students' integrated profiles, $80.9 \%$ of students had both clear MBTI personality types and STRONG occupation interest types. Further, $15.7 \%$ of students had a clear preference of MBTI personality types but unclear STRONG occupation interest types. In contrast, $3.4 \%$ of students had clear STRONG occupation interest types and unclear preference of MBTI personality type (Fig. 1).

\section{DISCUSSION}

One recent trend in medical education is graduates advancing in various professional specialties after medical as such careers have become more diverse. On selecting a career, direct or indirect experience in one's preselected career field would be a good opportunity to shape the final decision. We discussed more tailored career coaching methods for medical students using the integrated profile results of the MBTI personality type test and STRONG occupation interest types.

In this study, $15.7 \%$ of the premedical students of a medical college had unclear occupational interest, which is surprising. We normally assume that students who enter medical college have clear career goals, but our results show that this is not the case. Also, 3.3\% of students had an unclear preference of personality type, indicating that they have poor self-recognition or self-identity. Students with low preference levels must be followed closely, because they tend to have a biased weighting of item responses. Thus, in dealing with students with unclear preference levels, we must examine their self-identity level to plan a more tailored strategic counseling approach. A total of 29 students (16.1\%) had an unclear STRONG occupational interest, more than those with unclear MBTI personality types. Having an unclear STRONG occupational interest involves not knowing one's interest, being too restricted much, or having an indecisive character or low self-esteem. This may lead to indecisive selection of one's career path. Even for students who have already decided on a future major, they may lack information on their specific choice.

Based on the integrated profiles, there were no cases with unclear MBTI and STRONG types, which is fortunate. But, $15.7 \%$ had clear STRONG occupational interest but unclear preference of MBTI personality, and 3.4\% had clear STRONG occupational interest but unclear preference for MBTI personality type. These students had uncertain preferences, indicating that they must work on what they enjoy doing and are proficient in. Career coaching should be based on such results of integrated profiles. Some counseling strategies can be suggested for these two types of profiles. First, students with clear MBTI and unclear STRONG profiles must have the opportunity to determine one's interest, providing information on various careers and occupations, $15.7 \%$ of students had this profile, which we cannot ignore. Creating or providing a guide book that provides ample information on specialties to medical students after graduation and detailed information on each spe- 
cialty would be help students find a clearer path toward their career and will be a valuable resource for career counseling. Second, students with unclear MBTI and clear STRONG profiles may have a lot of stress or psychological concerns. Normally, medical students are under a lot of stress and pressure regarding their academic studies and expectations for high accomplishments $[14,15,16]$. Such situations prevent them from concentrating on their career and healthy lifestyles, which takes time. Therefore, psychological concerns must be solved, such as by tailored career coaching.

Using an integrated profile of MBTI personality and STRONG occupation interest types, we can develop tailored information for medical students that will help in career coaching and counseling in medical education. Future research is recommended, such as an analysis of actual career coaching cases using the integrated MBTI and STRONG profile. Also, by creating and using a tailored career guide book or coaching book for medical students, we can generate more useful information and strategies on detailed and tailored guidance in coaching the careers of medical students.

This study has several limitations. First, this study was limited to one medical college in Korea. Second, we did not double-check the actual concerns of the students in each profile. Nevertheless, this study confirmed current medical student personality types and occupation interests. Most studies have used either of these instruments, but our study used both, and no studies have implemented STRONG for medical students. This study proposes a method that can be used in career coaching for medical students and predicts the consequent changes in career coaching programs for medical education in the near future. Also, using two instruments instead of one helps us identify freshmen who are most in need of counseling for follow-up until graduation.
Acknowledgements: We, authors, appreciate Dr Win May's contribution on discussion and her insightful comments for this study.

Funding: None.

Conflicts of interest: None.

\section{REFERENCES}

1. Navarro AM, Taylor AD, Pokorny AP. Three innovative curricula for addressing medical students' career development. Acad Med 2011; 86: 72-76.

2. Sastre EA, Burke EE, Silverstein E, Kupperman A, Rymer JA, Davidson MA, Rodgers SM, Fleming AE. Improvements in medical school wellness and career counseling: a comparison of one-on-one advising to an Advisory College Program. Med Teach 2010; 32: e429e435.

3. Macaulay W, Mellman LA, Quest DO, Nichols GL, Haddad J Jr, Puchner PJ. The advisory dean program: a personalized approach to academic and career advising for medical students. Acad Med 2007; 82: 718-722.

4. Harris JA, McKay DW. Evaluation of medical careercounseling resources across Canada. Teach Learn Med 2012; 24: 29-35.

5. Barry PN, Fallat ME. Medical student mentorship in a university setting as a strategy for a career in surgery. Am Surg 2011; 77: 1432-1434.

6. McCord JH, McDonald R, Sippel RS, Leverson G, Mahvi DM, Weber SM. Surgical career choices: the vital impact of mentoring. J Surg Res 2009; 155: 136-141.

7. Zink BJ, Hammoud MM, Middleton E, Moroney D, Schigelone A. A comprehensive medical student career development program improves medical student satisfaction with career planning. Teach Learn Med 2007; 19: 55-60. 
8. Dorsey ER, Jarjoura D, Rutecki GW. The influence of controllable lifestyle and sex on the specialty choices of graduating U.S. medical students, 1996-2003. Acad Med 2005; 80: 791-796.

9. Fielding JR, Major NM, Mullan BF, Neutze JA, Shaffer K, Wilcox CB, Paynter L, Pisano ED. Choosing a specialty in medicine: female medical students and radiology. AJR Am J Roentgenol 2007; 188: 897-900.

10. Lambert EM, Holmboe ES. The relationship between specialty choice and gender of U.S. medical students, 1990-2003. Acad Med 2005; 80: 797-802.

11. Mutha S, Takayama JI, O’Neil EH. Insights into medical students' career choices based on third- and fourth-year students' focus-group discussions. Acad Med 1997; 72: 635-640.

12. Kim MJ, Chun IS, Kim EJ, Kim TJ. User's guide
STRONG \& MBTI. 2nd ed. Seoul, Korea: ASSESTA; 2006.

13. Kim JT, Kim MJ, Sim HS. User's guide STORNG interest inventory assessment. 2nd ed. Seoul, Korea: ASSESTA; 2005.

14. Dahlin M, Joneborg N, Runeson B. Stress and depression among medical students: a cross-sectional study. Med Educ 2005; 39: 594-604.

15. Ahn D, Park G, Baek KJ, Chung SI. Academic motivation, academic stress, and perceptions of academic performance in medical students. Korean J Med Educ 2007; 19: 59-71.

16. Lee KH, Ko Y, Kang KH, Lee HK, Kang J, Hur Y. Mental health and coping strategies among medical students. Korean J Med Educ 2012; 24: 55-63. 